\title{
UV light signature in conjunctival melanoma; not only skin should be protected from solar radiation
}

\author{
Journal of Human Genetics (2016) 61, 361-362; doi:10.1038/jhg.2015.152; published online 10 December 2015
}

Conjunctival melanoma represents $5 \%$ of ocular melanomas. It is a highly recurrent tumor leading to metastatic disease and death at 10 years in $25-30 \%$ of patients. ${ }^{1}$ Recent molecular investigations have indicated that conjunctival and cutaneous melanomas may share common features. ${ }^{2}$ For instance, epidemiological studies have shown an association between decreasing latitude and increasing incidence of conjunctival melanoma, ${ }^{3}$ suggesting that exposure to sunlight has a role in its etiology. ${ }^{4}$ However, strong molecular proof of such correlation has not been established. We hereby report the results of a genome-wide sequencing effort of two conjunctival melanomas documenting a strong ultraviolet (UV) mutation signature.

We performed high-coverage wholegenome sequencing (average read depth $=80 \mathrm{x}$, with $97.1 \%$ of the genome covered at least 40x) of two untreated perilimbic conjunctival melanomas occurring in two Caucasian women, aged 57 years (patient A) and 65 years (patient B) (Figures 1a and b). Somatic mutations were ascertained by comparing the DNA sequence of each tumor with their respective germline matches (blood leukocyte DNA). We identified a very high somatic mutation load composed of more than 96000 mutations in each tumor, resulting in an average genome-wide mutational rate of 30 somatic mutations per million DNA bases. On average, we detected 802 mutations in the coding regions of genes. The ratio of non-synonymous to synonymous variants was $1.59: 1$, showing a prominence of passenger mutations. Non-synonymous mutations were composed mainly of missense (90\%), followed by nonsense changes (7\%).
Moreover, detailed analysis of the mutation spectrum uncovered a majority of cytosine to thymine $(\mathrm{C}>\mathrm{T})$ transitions, occurring in 88 (patient A) and $83 \%$ (patient B) of the singlenucleotide substitutions in these tumors (Figure 1c). In addition, 80 and 100\% of these $\mathrm{C}>\mathrm{T}$ changes, respectively, occurred at the $3^{\prime}$ end of pyrimidine dinucleotides and CC $>$ TT changes represented $>70 \%$ of all tandem substitutions, showing the presence of a typical UV mutational signature. ${ }^{5}$

Altogether, our molecular findings support the occurrence of UV-induced DNA damage in conjunctival melanoma indicating a link between solar radiation and development of this tumor. Awareness should therefore be raised in the general population about the benefits of wearing UV-shielding eyeglasses, in addition to skin sunscreens, when exposed to sunlight.
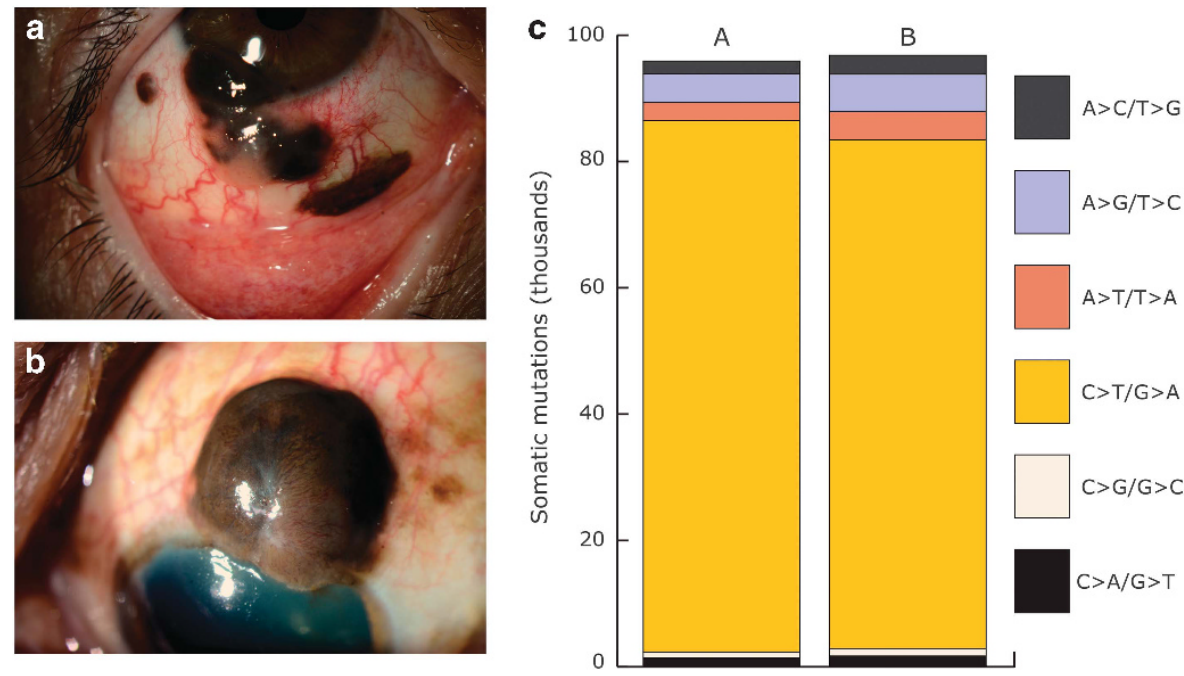

Figure 1 (a) A partially pigmented melanoma is seen in the inferior perilimbic area with extension onto the cornea. The isolated inferior and temporal pigmented areas were primary acquired melanosis (patient A). (b) A pigmented melanoma can be observed in the superior perilimbic area (patient B). (c) Mutation spectrum of the two conjunctival melanomas (A: patient A, B: patient B), showing a clear ultraviolet-induced DNA damage signature. No somatic mutations were detected in the melanoma-related genes BRAF and NRAS. 


\section{CONFLICT OF INTEREST}

The authors declare no conflict of interest.

\section{ACKNOWLEDGEMENTS}

This work was supported by the 'Fond'action contre le cancer' foundation, Switzerland. We wish to thank Complete Genomics (Mountain View, CA, USA) for providing the whole-genome sequencing discussed in this report.

Carlo Rivolta ${ }^{1}$, Beryl Royer-Bertrand ${ }^{1}$, Donata Rimoldi ${ }^{2}$, Ann Schalenbourg ${ }^{3}$, Leonidas Zografos ${ }^{3}$, Serge Leyvraz ${ }^{4}$ and Alexandre Moulin ${ }^{3}$

${ }^{1}$ Department of Medical Genetics, University of Lausanne, Lausanne, Switzerland; ${ }^{2}$ Ludwig Center for Cancer Research of the University of Lausanne, Épalinges, Switzerland; ${ }^{3}$ Department of Ophthalmology,
University of Lausanne, Jules Gonin Eye Hospital, Lausanne, Switzerland and ${ }^{4}$ Department of Oncology, Lausanne University Hospital, Lausanne, Switzerland E-mail: beryl.royer-bertrand@unil.ch

1 Missotten, G. S., Keijser, S., De Keizer, R. J. \& De Wolff-Rouendaal, D. Conjunctival melanoma in the Netherlands: a nationwide study. Invest. Ophthalmol. Vis. Sci. 46, 75-82 (2005).

2 Griewank, K. G., Westekemper, H., Murali, R., Mach, M., Schilling, B., Wiesner, T. et al. Conjunctival melanomas harbor BRAF and NRAS mutations and copy number changes similar to cutaneous and mucosal melanomas. Clin. Cancer Res. 19, 3143-3152 (2013).

3 Yu, G. P., Hu, D. N. \& McCormick, S. A. Latitude and incidence of ocular melanoma. Photochem. Photobiol. 82, 1621-1626 (2006).
4 Griewank, K. G., Murali, R., Schilling, B., Scholz, S., Sucker, A., Song, M. et al. TERT promoter mutations in ocular melanoma distinguish between conjunctival and uveal tumours. Br. J. Cancer 109, 497-501 (2013).

5 Ikehata, H. \& Ono, T. The mechanisms of UV mutagenesis. J. Radiat. Res. 52, 115-125 (2011).

(i) (2) (2) This work is licensed under a Creative Commons Attribution-

NonCommercial-ShareAlike 4.0 International License. The images or other third party material in this article are included in the article's Creative Commons license, unless indicated otherwise in the credit line; if the material is not included under the Creative Commons license, users will need to obtain permission from the license holder to reproduce the material. To view a copy of this license, visit http://creativecommons.org/ licenses/by-nc-sa/4.0/ 